\title{
Health and health behaviour among late adolescents in Southern Sri Lanka
}

\author{
Bilesha Perera $^{1}$, Truls Østbye ${ }^{2}$, Nayana Fernando ${ }^{3}$, Vathsala Abeygunawardena ${ }^{4}$, \\ PL Ariyananda ${ }^{5}$, Christopher Woods ${ }^{6}$ \\ ${ }^{1}$ Senior Lecturer, ${ }^{3}$ Lecturer, ${ }^{4}$ Study Coordinator, ${ }^{5}$ Professor, Faculty of Medicine, University of \\ Ruhuna, Galle, Sri Lanka. \\ ${ }^{2}$ Professor, ${ }^{6}$ Associate Professor, Duke University Medical Center, North Carolina, USA
}

\begin{abstract}
Objectives: To present the rationale and design of the Southern Province A-level School Health Survey, to identify health status and health behaviour patterns, and to examine gender differences in these factors, among late adolescent school children in Southern Sri Lanka.
\end{abstract}

Methods: A self-administered, anonymous questionnaire was used to obtain information on demographics, perceived health status, psychological well-being, substance use, physical activity, school violence, and sexual health. A two-stage cluster sampling method was used to select students from the three districts in the Southern Province.

Results: A total of 908 females and 903 males participated in the study. The majority (about $98 \%$ ) was aged 18 years and $99 \%$ were Sinhalese. Over $80 \%$ of both male and female participants reported self-perceived physical and mental health as "very good" or "good." Nearly $50 \%$ of both male and female respondents had experienced severe or moderate psychological distress in the 30-day period preceding the survey. Males were more likely to report substance use than females (Alcohol use: 10.5\% verses $1.8 \%$; Smoking: $5.1 \%$ verses $<1 \%$; Illegal drug use: $1.5 \%$ verses $<1 \%$ ). No gender difference was found in level of physical activity. About $64 \%$ of the males and $62 \%$ of the females were underweight. Males were more likely than females to be involved in violent activities at school $(60.1 \%$ verses $46.8 \%)$. About $7 \%$ of male and $6 \%$ of female students reported having had some form of heterosexual experience in the previous year.
Conclusions: In general, health status of this student population is good. Malnutrition, sexual and mental health issues, and issues relating to violence, however, require closer attention. Further, longitudinal and qualitative research is needed to identify causal factors associated with the unhealthy behavior patterns identified among these late adolescents.

\section{Introduction}

Although relatively healthy compared to other age groups, adolescents are vulnerable to a number of physical and mental health problems $[1,2]$. Chronic, as well as, acute health conditions such as diabetes, heart disease, depression, injuries, and sexually transmitted diseases are increasingly prevalent, and recognized, in adolescents [1-4]. However, mental health problems of adolescents are often neglected or not given adequate attention by medical practitioners or by health and education authorities because adolescents are generally considered less likely to develop psychological problems [3, 5]. In Sri Lanka, adolescents are facing a series of health challenges rooted in the environmental and political problems and in the economic and social disparities seen in the country [4-6]. A paucity of epidemiological health related data on adolescents in the country has further impeded the development and implementation of health promotion activities targeted at this age group [4,5]. Thus, there is a need to conduct micro and macro level epidemiological studies on adolescents to fill this lacuna. 
A survey was conducted by the Duke-Ruhuna collaborative research center at the Faculty of Medicine, University of Ruhuna, Galle to explore health and health behavior patterns in advanced level students in Southern Sri Lanka. The objective of this paper is to provide an overview of this school health survey, to present key indicators of health and health behavior among older adolescents in the area, and to evaluate whether there are important differences among males and females regarding these indicators.

\section{Materials and Methods}

\section{Study population and sample}

The target population for the survey was older adolescents in the three districts in the Southern Province. The random study sample was drawn from advanced level students from all public schools (single sex as well as mixed schools) in the province. A cluster sampling method was used to select the participants [7]. Within the sampled schools, all A-level classes (grade 11 and 12) were selected in the case of smaller schools; in larger schools, a maximum of 7 classes were sampled. All students in the sampled classes were invited to take part in the survey.

\section{Questionnaire and items}

A questionnaire, consisting of 138 items, was developed using common questions from other similar surveys or validated scales. Demographic data including sex, age, religion, ethnicity, height and weight, and substance use, physical and leisure time activities, sexual behavior, food habits, involvement in violent behavior in school and psychological and physical health of the participants constituted the components of the questionnaire. The General Well-Being Schedule (GWBS) was used to measure the level of distress among participants [8]. Internal consistency and reliability of the scale was determined using the alpha coefficient, which was 0.76 for the GWBS scale. Three population health researchers confirmed the face validity of the entire questionnaire. The questionnaire was pilot tested on 40 students not part of the main study. It took approximately 45 minutes to complete the questionnaire. The questionnaire was first developed in English, translated to Sinhala and finally back translated to English. Only the Sinhala version was administered to the students.

The questionnaires were introduced and distributed by a group of 12 trained research assistants who were either science or arts degree graduates. The respondents themselves completed the questionnaires during normal class period.

No personal identifiers were collected. Ethical approval for the survey was obtained from the Ethics Review Committee, Faculty of Medicine, Galle and from the Institutional Review Board, Duke University Medical Center, USA. Permission to conduct the survey in the selected schools was obtained from the Provincial Director of Education, Southern Province and from the Principals in each selected school. Data entry was completed using Microsoft Excel. Statistical Package for Social Sciences (SPSS) was used for data analysis.

\section{Results}

A total of 1936 students participated in the study. After cleaning and consistency-checking of the data set, analyses were completed using 1811 [female: 908 (50.1\%) and male: 903 (49.9\%) ] students. Ninety eight percent $(n=1778)$ of the students were aged 18 years. Nearly $98 \%$ of the participants were Sinhala-Buddhists. Families of the respondents were categorized into three income groups: low (monthly income less than or equal to Rs. 5,000), middle (monthly income Rs. 5,001 - Rs. 30,000) and upper (monthly income greater than Rs.30,000). Of the students $65.5 \%$ were from the middle income families followed by low income $(25.5 \%)$ and upper income families $(9 \%)$.

The different health and health behavior indicators are presented and compared by gender, using student's t-test for continuous variables and chi-square test for categorical variables (Table 1). 
Table 1 - Health indicator by Gender $(N=1811)$

\begin{tabular}{|c|c|c|c|}
\hline \multirow[t]{2}{*}{ Variable } & \multicolumn{2}{|l|}{ Gender } & \multirow[b]{2}{*}{ Significance } \\
\hline & $\begin{array}{l}\text { Female } \\
(\mathrm{n}=908)^{*}\end{array}$ & $\begin{array}{l}\text { Male } \\
(\mathrm{n}=903)^{*}\end{array}$ & \\
\hline $\begin{array}{l}\text { Perceived Physical Health } \\
\text { Very Good or Good } \\
\text { Moderate or poor }\end{array}$ & $\begin{array}{l}76.5 \% \\
23.5 \% \\
\end{array}$ & $\begin{array}{l}79.0 \% \\
21.0 \%\end{array}$ & $P=0.213$ \\
\hline $\begin{array}{l}\text { Perceived Psychological Health } \\
\text { Very Good or Good } \\
\text { Moderate or poor }\end{array}$ & $\begin{array}{l}78.0 \% \\
22.0 \%\end{array}$ & $\begin{array}{l}80.2 \% \\
19.8 \%\end{array}$ & $P=0.251$ \\
\hline $\begin{array}{l}\text { Distress } \\
\text { Severe or moderate } \\
\text { Positive well being }\end{array}$ & $\begin{array}{l}55.1 \% \\
44.9 \% \\
\end{array}$ & $\begin{array}{l}53.8 \% \\
46.2 \% \\
\end{array}$ & $p=0.576$ \\
\hline Body Mass Index (BMI) (mean) & $18.17(S D=3.1)$ & $18.27(S D=3.5)$ & $P=0.544$ \\
\hline $\begin{array}{l}\text { Weight } \\
\text { Underweight } \\
\text { Overweight or Obese } \\
\text { Normal weight } \\
\end{array}$ & $\begin{array}{l}61.6 \% \\
3.1 \% \\
35.3 \% \\
\end{array}$ & $\begin{array}{l}63.9 \% \\
4.7 \% \\
31.4 \% \\
\end{array}$ & $P=0.120$ \\
\hline $\begin{array}{l}\text { Rigorous Exercise (last week) } \\
1 \text { day or None } \\
2 \text { or more days }\end{array}$ & $\begin{array}{l}14.7 \% \\
85.3 \%\end{array}$ & $\begin{array}{l}17.1 \% \\
82.9 \%\end{array}$ & $P=0.162$ \\
\hline $\begin{array}{l}\text { Watching TV (during a normal school day) } \\
\text { Less than } 2 \text { hours } \\
2 \text { hours or more }\end{array}$ & $\begin{array}{l}51.3 \% \\
48.7 \% \\
\end{array}$ & $\begin{array}{l}40.8 \% \\
59.2 \%\end{array}$ & $p<0.001$ \\
\hline $\begin{array}{l}\text { Smoking } \\
\text { Life time } \\
\text { Monthly } \\
\end{array}$ & $\begin{array}{l}2.2 \% \\
<1 \% \\
\end{array}$ & $\begin{array}{l}27.1 \% \\
5.1 \%\end{array}$ & $\begin{array}{l}p<0.001 \\
p<0.001\end{array}$ \\
\hline $\begin{array}{l}\text { Alcohol use } \\
\text { Life time } \\
\text { Monthly } \\
\end{array}$ & $\begin{array}{l}12.7 \% \\
1.8 \%\end{array}$ & $\begin{array}{l}37.1 \% \\
10.5 \%\end{array}$ & $\begin{array}{l}p<00.01 \\
p<0.001\end{array}$ \\
\hline $\begin{array}{l}\text { Illegal drug use } \\
\text { Life time } \\
\text { Monthly }\end{array}$ & $\begin{array}{l}1.6 \% \\
<0.1 \%\end{array}$ & $\begin{array}{l}9.5 \% \\
1.5 \% \\
\end{array}$ & $\begin{array}{l}p<0.001 \\
p<0.024\end{array}$ \\
\hline Involved in heterosexual activity (last year) & $5.6 \%$ & $6.6 \%$ & $P=0.367$ \\
\hline Involved in homosexual activity (last year) & $<1 \%$ & $5.7 \%$ & $p<0.001$ \\
\hline Experienced violent activities at school & $46.8 \%$ & $60.1 \%$ & $p<0.001$ \\
\hline $\begin{array}{l}\text { Mean number of days absent from school } \\
\text { (past month) }\end{array}$ & $2.5(S D=3.38)$ & $3.0(S D=4.12)$ & $p<0.015$ \\
\hline
\end{tabular}

* Percentages were calculated by omitting non-responses.

A similar percentage of both male students (79\%) and female $(76.5 \%)$ students reported perceived physical health as "good" or "very good", and the corresponding figures for self-perceived psychological health were $78 \%$ and $80.2 \%$ respectively. However, approximately $55 \%$ of both male and female students had experienced moderate or severe distress during the 30-day period preceding the survey. The majority (about $62 \%$ of both male and female respondents) were underweight (Body Mass Index $<18.5$ ) and about $4 \%$ were over-weight or obese (Body Mass Index $>25$ ). Over $80 \%$ of both male and female respondents had engaged in rigorous physical activity (i.e., physical activity for at least 20 minutes that made the student sweat and breathe hard) at least two days in the 7 days preceding the survey. More male respondents $(59.2 \%)$ compared to female respondents $(48.7 \%)$ reported that they had watched TV two or more hours in a normal school day. Male students were more likely than their female counterparts to report having used tobacco products, alcohol and illegal drugs. About $6 \%$ of both male and female respondents reported having been involved in some form of sexual activity with an opposite sex partner/s in the 12 months preceding the survey. Significantly higher percentage of male 
respondents $(5.7 \%)$ compared to female respondents $(<1 \%)$ reported having been involved in some form of sexual activity with a same sex partner/s in the 12 months preceding the survey. Significantly higher proportion of male participants $(60.1 \%)$ compared to female participants $(46.8 \%)$ reported that they had experienced verbal or physical violence on the school property at least once in the previous 12 months. There was a significant gender difference in mean number of days absent from school due to any illness or sickness: 2.5 for females and 3 for males.

\section{Discussion}

The overall health status of this adolescent population is good. Similarly, the health behavior patterns reported are positive. However, there are several areas in need of attention from health providers and teachers as well as health and education authorities in the country.

As have been highlighted by others $[9,10]$, distress levels among late adolescents in Sri Lanka are relatively high compared to other adolescent and young age groups in the world. Students experience a number of stressful events in their home and school environments that may predispose them to the development of depression and other psychological disorders. Risk and protective factors of adolescent stress should be identified and more attention should be directed towards improving the psychological health of adolescents.

The proportion of underweight students observed in this sample may indicate the need of further study to distinguish between those students who may be just 'skinny' and those who may be malnourished. Interventions in improving food habits among students should be considered. Poverty, poor eating habits and lack of knowledge of a healthy diet may be the major contributing factors for malnutrition and obesity among adolescents, as has been reported elsewhere [1,3].

As expected, alcohol, tobacco, and illegal drug use was more prevalent among male students [9, 11]. Although the consumption rates are lower than rates found in developed countries, sociocultural changes occurring in the country, with an increasing number of adolescents adapting a westernized life-style, substance use prevention programs should target not only adolescents but also very young children to challenge any positive social image such unhealthy habits may have.

Recent studies carried out in Sri Lanka indicate that attitudes and practices of adolescents relating to sex have changed greatly in recent years [12-13]. Many male adolescents in Sri Lanka have easy access to pornographic publications or adult sites in the internet. Results of this study have shown that a considerable proportion of both male and female students have had sexual experiences with others. Cultural taboos restrict adolescents from getting proper and detailed information about sexual health, and with limited access to buying condoms, a substantial number of adolescents may be at risk of contracting sexually transmitted diseases or end up with unwanted pregnancies. School counseling services need to be expanded by providing services of trained counselors for public schools.

Another area in need of attention is violent behavior in schools. There is a connection between exposure to violence in the media and subsequent violent behavior in the school [14]. Most adolescents in the country have little or no restrictions in watching TV programs that they prefer. The results of this survey indicated that a substantial proportion of adolescents have been watching TV for two or more hours per day. Therefore, it is probable that there is a causeeffect relationship between exposure to TV and violent behavior in schools with respect to this study population. De Silva and Jayasinghe reported that physical punishment by teachers appears to be still a common feature in Sri Lankan schools [15]. Involvement in or witnessing physical or verbal violent incidents in any form may adversely affect the psychological health of students. Results of this study have shown that a considerable proportion of students were exposed to verbal or physical violent incidents on school premises. This area needs further research to identify causative factors of 
school violence and interventions are needed to reverse this trend.

Males were more likely than females to be absent from attending school classes due to illnesses or sicknesses. Type of illnesses and injuries that prevent student from attending school classes regularly needs to be identified.

There are several limitations in this study. All information in this study was obtained via selfreport and the sensitive nature of some of the questions may have resulted in inaccurate responses or underestimates of some of the prevalence figures. However, the anonymous nature of the survey should minimize underreporting bias. In some schools areas, instead of attending classes in the regular schools, students tend to attend private tuition classes because of the shortage of teachers in the regular schools. Thus, we were not able to survey all students in some selected schools - the absent students might have shown different health and health behavior patterns than those surveyed. Further we cannot generalize these results to all late adolescents: adolescents no longer in schools were not included in study sample and are also likely to have different health behavior patterns from those included. However, the large number of students from several schools in the three districts in the southern province indicates that these findings are valid and generalizable to all A-level students in this area.

In conclusion, late adolescent school children in the Southern Province appear healthy and experience a relatively healthy life style compared to many other late adolescent groups across the world. However, potential malnutrition, mental problems and violent behaviors were identified as important health issues in need of urgent attention.

\section{Acknowledgements}

This study was funded by the Tsunami Fund established by the Chancellor of Duke University Medical Center, and by the Hubert Yeargen Center for Global Health. Thanks to all research assistants for their help with the field work and the data collection

\section{References}

1. World Health Organization. The second decade: Improving adolescent health and development, Geneva, Switzerland: WHO, 2001.

2. Rosen JE. Adolescent health and development- A resource guide for world bank operations staff and government counterparts, The World Bank, Washington DC, 2004.

3. World Health Organization. World Health Report 2004, Geneva, Switzerland: WHO, 2004.

4. Prior M, Virasighe S, Smart D. Behavioral problems in Sri Lankan School Children: associations with socioeconomic status, age, gender, academic progress, ethnicity and religion. Social Psychiatry and Psychiatric Epidemiology, 2005, 40(8):654-62.

5. De Silva WI, Somanathan A, Eriyagama V. Adolescent and youth reproductive health in Sri Lanka. Institute of Policy Studies in Sri Lanka, Colombo, 2003.

6. Department of Health Services. Annual Health Bulletin 2004, Department of Health Services, Colombo, 2005.

7. Bennett S, Woods T, Liyanage WM, Smith DL. A simplified general method for cluster sample surveys of health in developing countries. World Health Statistics Quarterly 1991, 44: 98-106.

8. McDowell I, Newell C. Measuring Health - A guide to rating scales and Questionnaires, Oxford University Press, New York, 1996.

9. Perera B, Torabi MR, Jayawardana G, Pallethanna N. Depressive symptoms among adolescents in Sri Lanka: Prevalence and behavioral correlates. Journal of Adolescent Health 2006, 39: 144-146.

10. Kuruppuarachchi KALA, Kuruppuarchchi KAJM, Wijeratne S, Williams SS. Psychological distress among students from five universities in Sri Lanka. Ceylon Medical Journal 2002; 47: 13-15.

11. Perera B, Fonseka P, Ekanayake R, Lelwala E. Smoking in Adults in Sri lanka: Prevalence and attitudes. Asia Pacific Journal of Public Health 2005, 17(1): 40-45.

12. De Silva WI. Socio-economic change and adolescent issues in the asian and pacific region in Report and recommendations of the exper group meeting on adolescents: Implications of population trends, environment and development, Asian population studies series 149: 46-81, Bangkok: ESCAP 1998.

13. Perera B, Reece M. Sexual behavior of young adults in Sri Lanka: Implications for HIV prevention, AIDS Care 2006, 18(5): 497-500.

14. Lee E, Kim M. Exposue to media violence and bullying at school: Mediating influences of anger and contact with delinquent friends. Psychological Reports 2004, 95: 659-672.

15. De Silva D, Jayasinghe S. Do schools promote violence in Sri Lanka? The Ceylon Medical Journal 2004, 49: 21-23. 